\title{
Geographic Variation in Network Structure of a Nearctic Aquatic Food Web
}

\section{Citation}

Baiser, Benjamin, Nicholas J. Gotelli, Hannah L. Buckley, Thomas E. Miller, and Aaron M. Ellison. 2011. Geographic Variation in Network Structure of a Nearctic Aquatic Food Web. Global Ecology and Biogeography. doi: 10.1111/j.1466-8238.2011.00705.x.

\section{Published Version}

doi:10.1111/j.1466-8238.2011.00705.x

\section{Permanent link}

http://nrs.harvard.edu/urn-3:HUL.InstRepos:8298848

\section{Terms of Use}

This article was downloaded from Harvard University's DASH repository, and is made available under the terms and conditions applicable to Other Posted Material, as set forth at http:// nrs.harvard.edu/urn-3:HUL.InstRepos:dash.current.terms-of-use\#LAA

\section{Share Your Story}

The Harvard community has made this article openly available.

Please share how this access benefits you. Submit a story.

\section{Accessibility}


1 Geographic Variation in Network Structure of a Nearctic Aquatic

\author{
Food Web
}

4 Benjamin Baiser ${ }^{1}$, Nicholas J. Gotelli ${ }^{2}$, Hannah L. Buckley ${ }^{3}$, Thomas E. Miller ${ }^{4}$

5 Aaron M. Ellison ${ }^{1}$

6

$7 \quad{ }^{1}$ Harvard University, Harvard Forest, 324 N. Main St., Petersham, MA 01366, USA

$8 \quad{ }^{2}$ Department of Biology, University of Vermont, Burlington, VT 05405, USA

$9 \quad{ }^{3}$ Department of Ecology, P.O. Box 84, Lincoln University, Canterbury, New Zealand

10

${ }^{4}$ Department of Biological Science, Florida State University, Tallahassee, FL 32306-4295, USA

11

12 *Correspondence: Harvard University, Harvard Forest, 324 N. Main St., Petersham, MA 01366, USA

13 E-mail: bbaiser@fas.harvard.edu, Phone : 1-978-756-6155, Fax:1-978-724-3595

14

15

Article type: Research Paper

Running title: Network structure in a cosmopolitan food web

17

18

19

20 


\section{ABSTRACT}

24 Aim The network structure of food webs plays an important role in the maintenance of diversity and 25 ecosystem functioning in ecological communities. Previous research has found that ecosystem size, 26 resource availability, assembly history, and biotic interactions can potentially drive food web structure.

27 However, the relative influence of climatic variables that drive broad-scale biogeographic patterns of 28 species richness and composition has not been explored for food web structure. In this study, we assess 29 the influence of broad-scale climatic variables in addition to known drivers of food web structure on 30 replicate observations of a single aquatic food web, sampled from the leaves of the pitcher plant 31 (Sarracenia purpurea), at different geographic sites across a broad latitudinal and climatic range.

33 Location Using standardized sampling methods, we conducted an extensive "snapshot" survey of 780 replicated aquatic food webs collected from the leaves of the pitcher plant Sarracenia purpurea at 39 sites from northern Florida to Newfoundland and westward to eastern British Columbia.

37 Methods We tested for correlations of 15 measures of food web structure at the pitcher and site scales with geographic variation in temperature and precipitation, concentrations of nutrients from atmospheric mosquito (Wyeomyia smithii), a potential keystone species.

41

42 Results At the scale of a single pitcher plant leaf, linkage density, species richness, measures of chain

43 length, and the proportion of omnivores in a web increased with pitcher volume. Linkage density and 44 species richness were greater at high latitude sites which experience lower mean temperatures and 
45 precipitation, and higher annual variation in both of these variables. At the site scale, variation in eight of 46 the 15 food web metrics decreased at higher latitudes and variation in measures of chain length increased 47 with the abundance of mosquitoes.

48 Main Conclusions Ecosystem size and climatic variables related to latitude were most highly correlated 49 with network structure of the Sarracenia food web. However, even the best-fitting models explained less 50 than $40 \%$ of the variation in food web structure, in spite of large sample sizes, thorough standardized 51 sampling, and the large geographic extent of the survey. In contrast to biogeographic patterns of species 52 richness, food web structure was largely independent broad-scale climatic variables. The large proportion 53 of unexplained variance in our analyses suggests that stochastic assembly may be an important 54 determinant of local food web structure.

55

56

57 Key Words: Biogeography, chain length, food web, keystone predation, network structure, Sarracenia 58 purpurea

59

60 
63 Understanding the causes and consequences of food web structure is a central focus of community

64 ecology (Hairston et al., 1960; May, 1973; Pimm, 1982; Fretwell, 1987; Beckerman et al., 2006; Schmitz,

65 2010). Experimental studies have documented that food web structure is influenced by ecosystem size

66 (Spencer \&Warren, 1996; Post et al., 2000; Takimoto et al., 2008; McHugh et al., 2010), the presence of

67 keystone predators (Paine, 1969; Woodward et al., 2008), disturbance (Power et al., 1996; Marks et al.,

68 2000; McHugh et al., 2010), productivity (Townsend et al., 1998; Arim et al., 2007), and the availability

69 of nutrients and resources (Jenkins et al., 1992; Kaunzinger \& Morin, 1998). Literature compilations and

70 meta-analyses of studies of food web structure also have demonstrated that many food web metrics are

71 scale dependent (Schoener, 1989; Martinez, 1993; Martinez \& Lawton, 1995), that web connectance (the

72 proportion of possible links realized) is constrained between 0.03 and 0.33 (Dunne, 2002a), and that food

73 webs generally do not exhibit small-world network properties (Comacho et al., 2002; Dunne et al.,

74 2002b). However, it is difficult to infer general mechanisms from the results of single field experiments or

75 meta-analyses because of differences in the spatial and temporal scale of the different studies, and

76 differences in the collection, processing, and modeling of the raw data.

77 Here, we adopt a third strategy for understanding the control of food web structure. We test

78 previously proposed correlations of food web structure with replicate observations of a single food web

79 sampled at different geographic sites across a broad latitudinal and climatic range. We examine

80 associations between metrics of food web structure, climatic variables related to precipitation and

81 temperature that are strongly correlated to latitude, and potential causal variables such as nutrient inputs,

82 ecosystem size, and the abundance of potential keystone species. Taking such an approach in North

83 American lakes, Post et al. (2000) showed that food chain length is positively correlated with ecosystem

84 size. Similarly, Schmitz $(2006 ; 2010)$ used old-field food webs to show that trophic structure and adaptive

85 foraging influence $\mathrm{N}$ mineralization rate, plant biomass production, and supply rate of solar radiation.

86 Kitching (1987) found no relationship between tree-hole size and food web structure in Australian tree- 
87 hole communities. However, this kind of replicated sampling of a single food web is uncommon because

88 the composition of food webs normally varies extensively across sites, the large spatial extent of most

89 food webs makes it difficult or even impossible to sample all the organisms and their feeding interactions

90 in replicated food webs, and the spatial boundaries of most local food webs are often arbitrary and poorly

91 defined.

92 We assessed variation in the structure of a single aquatic food web that can be effectively and

93 thoroughly sampled over a large geographic scale: the invertebrate food web associated with the pitcher

94 plant Sarracenia purpurea L. (Buckley et al., 2003). Each of the cupped leaves of this plant holds up to

$95 \sim 50 \mathrm{ml}$ of water and supports a small, but fully-functional detritus-based food web of insect larvae, other

96 aquatic invertebrates (most commonly mites, rotifers, and copepods), protozoa, and microbes; captured

97 insect prey is the resource base for this donor-controlled food web (Addicott, 1974; Butler et al., 2008).

98 The Sarracenia food web has been an ideal model system for experimental studies of the effects of prey

99 resources (Kneitel \& Miller, 2002; Miller et al., 2002; Butler et al., 2008; Hoekman, 2010a), predators

100 (Addicott, 1974; Miller et al., 2003; Kneitel, 2007), habitat structure (Ellison et al., 2003), habitat volume

101 (Gotelli \& Ellison, 2006), and climate change (Hoekman, 2010b) on food web dynamics. Perhaps most

102 importantly for the results presented here, the Sarracenia food web has remarkably high similarity in

103 species composition of macroinvertebrates across the entire range of the host plant (Buckley et al., 2003;

104 2010). Finally, because this food web is spatially constrained within the small pools of rainwater that

105 collects in Sarracenia pitchers, it is easy to thoroughly sample the organisms in replicated webs.

We analyze an extensive "snapshot" data set of 780 Sarracenia webs sampled in 2001 from 39

107 sites throughout North America (western Canada to the Florida panhandle; Fig.1). Previous analyses of

108 this data set have established geographic trends in species richness, composition, and abundance of

109 individual taxa (Buckley et al., 2003; 2010). Here, we turn our focus to network structure and metrics that

110 summarize linkages and interactions among species within the Sarracenia food web. We calculated four

111 categories of metrics: those related to complexity, food chain length, types of taxa, and variation in 
112 trophic strategy (Table 1). We explore how the network structure of the Sarracenia food web varies

113 systematically with broad-scale climate variables that are correlated with latitudinal patterns of species

114 richness in this food web (e.g. mean temperature, annual precipitation), concentrations of nutrients from

115 atmospheric nitrogen deposition that limit plant (= food web habitat) growth (Ellison, 2006), plant size

116 and shape (Ellison \& Gotelli, 2002; Ellison et al., 2004), and three additional potential predictors of food

117 web structure (resource availability, ecosystem size, and the abundances of a potential keystone species).

118 We developed predictions of how food web structure would be related to known drivers (Post,

119 2002). Although Post's (2002) framework specifically addresses measures of food chain length, we

120 extended our analysis to several measures of food web complexity (Table 1). This is justified by the fact

121 that many of the secondary consumers and top predators in the Sarracenia food web are omnivores (Fig.

122 2) and as a result, measures of food chain length and complexity are highly correlated in this system

123 (Table 2, Fig. 3). Furthermore, in an analysis of 14 well-studied webs (Vermatt et al. 2009), food chain

124 length, the proportion of omnivores, and several measures of web complexity were positively correlated.

125 Our first prediction is that food chain length and complexity of the Sarracenia food web will increase

126 with potential resource availability (measured by microbial abundance, which is sensitive to prey inputs;

127 Kneitel \& Miller, 2002; Miller et al., 2002; Hoekman, 2010a). Second, chain length and complexity will

128 increase with habitat volume (measured as the volume of fluid in an individual pitcher plant leaf; Spencer

129 \& Warren, 1996; Post et al., 2000; Gotelli \& Ellison, 2006). Third, atmospheric nitrogen deposition,

130 which alters leaf morphology such that pitchers have smaller openings and tubes (Ellison \& Gotelli,

131 2002), will decrease chain length and complexity. Fourth, we predict that chain length and complexity

132 will increase with the presence of the larvae of the pitcher-plant mosquito, Wyeomyia smithii (Coq.), an

133 important filter-feeding predator in this system (Cochran-Stafira \& von Ende, 1998; Kneitel \& Miller,

134 2002; Gotelli \& Ellison, 2006; Peterson et al., 2008).

135 In addition to these predictors of food web structure, we also determined what percentage of the

136 variance in food web structure could be accounted for by a suite of broad-scale climatic variables (List 
and definitions of climate variables available in appendix S1) that are highly correlated with latitude across our study sites. In the Sarracenia food web, total species richness is greater at higher latitudes that generally experience lower and more variable temperatures along with lower and more variable amounts of precipitation (Buckley et al., 2003; 2010). We predict that food chain length and complexity will

141 increase with latitude due to the greater probability of omnivore and top predator presence in high latitude

142 species-rich webs. Our final prediction is based on the previous finding that within-site compositional 143 turnover shows an inverse relationship with latitude (Buckley et al., 2010). We predict that within-site 144 variability in web structure will track compositional turnover and increase at lower latitudes due to the 145 lack of trophic redundancy in the low latitude species-poor pools (Baiser \&Lockwood 2011).

\section{METHODS}

\section{The Sarracenia food web}

148 The food web inhabiting the aquatic microhabitat in the leaves of the northern pitcher plant is comprised 149 of microbes, protozoa, the bdelloid rotifer Habrotrocha rosa Donner (Bledzki \& Ellison, 2003), and a suite of obligate arthropods: the mite Sarraceniopus gibsoni (Nesbitt), and aquatic larvae of the pitcherplant mosquito Wyeomyia smithii, the midge Metriocnemus knabi (Coq.) and the sarcophagid fly Fletcherimyia fletcheri (Aldrich) (Addicott, 1974). Less common members of this assemblage include loricate rotifers, cladocerans, copepods, amphipods, nematodes, and multicellular algae (Adicott, 1974; Harvey \& Miller, 1996; Hamilton et al., 2000; Bledzki \& Ellison, 2003).

Feeding interactions in the Sarracenia food web center on a detritus "processing chain"

156 (Bradshaw and Creelman, 1984; Heard, 1994). Prey items that are captured by the plant are shredded by 157 the midge and the sarcophagid fly into particulate organic matter (POM). Bacteria directly decompose prey items and also consume POM. Bacteria are preyed upon by a suite of intraguild predators including protozoa, rotifers, Wyeomyia smithii, and Fletcherimyia fletcheri (Fig. 2). W. smithii, and late instar F. fletcheri are the top predators in this 5- level food web (Fig. 2). 


\section{Data collection}

162 We sampled 20 pitchers at each of 39 sites for a total of 780 pitchers across the range of S. purpurea (Fig.

163 1). We determined the abundances of invertebrates, rotifers, protozoa, and bacteria in each pitcher. We 164 counted and identified all invertebrates in each pitcher and rotifers and protozoa in 0.1-mL sub-samples 165 using a phase-contrast scope at 100x. Protozoa were identified to genus where possible and unidentified 166 protozoa were not used in food web calculations (there were 16 unknown protozoa, 13 of which occurred 167 in less than $2 \%$ of pitchers and three which occurred in 6-18\% of pitchers). Bacterial abundances were 168 estimated using serial dilutions $\left(10^{-5}\right.$ and $\left.10^{-7}\right)$ for each leaf and plating out samples on half-strength Luria 169 broth agar. Thus, only plate culturable bacteria were included and identified by colony morphotypes. We 170 calculated the density of the aforementioned taxonomic groups as abundance/mL in each pitcher. In total,

17175 taxa were included in web calculations (see food web metrics below). We determined latitude for each 172 site using the satellite global positioning system and recorded the total volume of pitcher fluid for each 173 pitcher (see Buckley et al., 2003 and 2010 for details on site selection, leaf selection, sampling protocol, 174 and a complete list of species found in all food webs).

\section{Food web metrics}

176 Feeding interactions (hereafter links) between the species of the Sarracenia food web were assigned 177 based on previous studies (Addicott, 1974; Forsyth \& Robertson, 1975; Heard, 1994; Cochran-Stafira \& 178 von Ende, 1998; Miller et al., 2002; Butler et al., 2008) and direct observation. We constructed an $n \times 2$ 179 matrix for each of the 780 food webs, where the $n$ rows are the number links; the first column of the 180 matrix contains the predator species identity and the second column contains the prey species identity for 181 each link. We used Network3D (Williams, 2010) to calculate a suite of 15 metrics that characterize 182 complexity, chain length, type of taxa, and variation in trophic strategy for the Sarracenia food web 183 (Table 1). Because metrics for most well studied food webs co-vary to some degree (Vermatt et al., 
2009), we used principal components analysis (prcomp in R version 2.11.1; R Development Core Team, 2010) to account for covariance structure of the food web metrics.

\section{Nitrogen data}

187 Pitcher plants receive atmospheric $\mathrm{N}$ (in the form of $\mathrm{NH}_{4}$ and $\mathrm{NO}_{3}$ ) from rain and snowmelt that fill the 188 pitchers. This atmospheric deposition can affect pitcher morphology and habitat structure for the food web (Ellison \& Gotelli, 2002), and pitcher plant population dynamics (Gotelli \& Ellison, 2002). We estimated deposition levels at each sampling site during the year of the survey to investigate these potential effects on food web structure. We used nitrogen deposition from National Atmospheric Deposition Data (NADP) monitoring stations that were closest to our sample sites in the United States sites. Therefore, for consistency, we estimated $\mathrm{N}$ deposition (total $\mathrm{N}=\mathrm{NH}_{4}+\mathrm{NO}_{3}$ as precipitationweighted mean concentration in $\mathrm{mg} / \mathrm{L}$ ) at all our sites (i.e. United States + Canadian sites) in the summer quarter (July-September) using the AURAMS model (Moran et al,. 2008) and used this estimate as a predictor variable for all sites in our analyses of Sarracenia food webs The estimates for United States sites were well-correlated with empirical NADP data $(r=0.66, p<0.0001)$, and we assumed similar accuracy for Canadian sites. Further details on modeling N deposition are given in appendix S2.

\section{Climate Data}

201 Spatially referenced climate data for all sites were obtained using the program ANUSPLIN from the 202 Landscape Analysis and Application Section of the Canadian Forest Service (McKenney et al., 2006).

203 Climate data for points nearest to the study site locations were queried in ArcGIS 9.0. We included 10 204 climate variables that quantify precipitation and temperature across our 39 sites (Appendix S1). The 10 205 climate variables and latitude were highly correlated (see appendix S3 for correlation matrix). To account 206 for the interdependency of these measures, we conducted a principal components analysis (prcomp in $\mathrm{R}$ version 2.11.1; R Development Core Team, 2010) and used the first two principal components axis (PC1 
and PC2) as predictor variables. Climate variables and latitude were transformed to standard deviation units for the principal components analysis. To insure that any one climate variable did not account for

210 the majority of the variation in a given food web metric, we ran a set of preliminary univariate regressions

211 with each climate variable, latitude, PC1, and PC 2 as predictor variables and food web metrics as

212 response variables. We ranked models using the Akaike Information Criterion (AIC), and used the AIC

213 score to select the best fitting model(s) among the candidate set (Burnham \&Anderson, 2002). If any

214 single climate variable had a $\triangle \mathrm{AIC}<2$ when compared to the first primary component axis (PC1), we

215 selected that climate variable for further consideration in the regression models described below. If no

216 single variable distinguished itself as a better fit $(\triangle \mathrm{AIC}<2)$ than $\mathrm{PC} 1, \mathrm{PC} 1$ was selected for further

217 consideration in the regression models described below. PC1 was the climate variable used in regression 218 models for all but one case.

\section{Data analyses}

\section{$221 \quad$ Pitcher scale}

222 We used linear mixed effects models (function 'lme' in package 'nlme' in R v.2.11.1) to assess the

223 influence of predictor variables on food web structure for the 780 individual pitchers (the pitcher scale of

224 analysis). We used food web metrics as response variables, site as a random effect, and PC1, pitcher

225 volume, nitrogen deposition, mosquito abundance, and bacterial abundance as fixed effects for the

226 pitcher-scale analyses.

We built a set of candidate models for each response variable that included a null model (i.e.

228 random intercept only), global model (with random intercept and all predictor variables entered),

229 univariate models for each predictor variable, and all subsets of variables that had a $P$-value $<0.1$ for the

230 slope coefficient in both the global and univariate models (model structure is given in appendix S4). We

231 ranked models using the Akaike Information Criterion (AIC), and used the AIC score to select the best 
fitting model(s) among the candidate set (Burnham \&Anderson, 2002). We calculated the variance explained $\left(\mathrm{R}^{2}\right)$ by the fixed effects in this mixed-effects model using Xu's (2003) method (see appendix

234 S5 for calculation).

Site scale

Variation in species richness and compositional turnover are greater within sites than across sites in the Sarracenia food web (Buckley et al., 2010). Therefore, to measure variation in food web structure within sites, we calculated the coefficient of variation (CV) of each web metric in the 20 webs at each of our 39 sites (site scale). We term this measure structural turnover and use it in the same sense as compositional turnover (i.e. $\beta$-diversity). High structural turnover means that when moving from one web to the next we are likely to encounter different network structure; high structural turnover results in a high CV at that site. Low structural turnover (measured as a low CV) means that web structure is similar from pitcher to pitcher within a single site.

We used linear models ( $\mathrm{lm}$ in R v.2.11.1) to assess the influence of predictor variables on 245 structural turnover at each of our 39 sites. We regressed structural turnover (the CV of each food web metric for the 20 pitchers at each of the 39 sites) on PC1, and the CVs of pitcher volume, mosquito 247 abundance, and bacterial abundance. The model for the food web metric Top included the climate variable $\mathrm{CV}$ of precipitation instead of PC1 based on the climate variable model selection (See Climate Data). We used the CV of pitcher volume, mosquito abundance, and bacterial abundance for this analysis because we were interested in how pitcher-to-pitcher variation of predictor variables within each site was correlated with pitcher-to-pitcher variation in food web metrics across all pitchers within each site.

We built a set of candidate models for each response variable that included a global model,

253 univariate models for each predictor variable, and all subsets of variables that had a $P$-value $<0.1$ for the 254 slope coefficient in both the global and univariate models. We ranked models using the Akaike Information Criterion (AIC), and used this score to select the best fitting model(s) among the candidate 
set (Burnham \&Anderson, 2002). We calculated the adjusted $\mathrm{R}^{2}$ to determine the proportion of variance

257 explained by each model.

Predictor variables

259 The correlations among predictor variables had correlation coefficients $<0.4$. All variables were

260 transformed into standard deviation units (positive values indicate observations that were greater than the 261 mean and negative values were less than the mean) for the pitcher-scale analyses except for PC1. N 262 deposition was also transformed to standard deviation units for the site-scale analyses.

264 RESULTS

\section{Principal components analysis of pitcher-scale variation in food web metrics}

266 The first two principal components explained $70 \%$ of the variation in network structure for the set of 780

267 Sarracenia food webs. The first principal axis (PC1) explained $45 \%$ of the variation and was related to 268 complexity and chain length. This axis was negatively correlated with metrics related to complexity (e.g.

269 connectance, species richness, links per species) and chain length (e.g. mean trophic level, chain length)

270 (Table 2). Percentage of omnivores and intermediate species were also negatively correlated with PC1

271 (Table 2). Webs with negative scores on PC1 were species-rich and contained many omnivores, which

272 increased chain length, linkage density, and connectance (Fig 3a). PC1 was positively correlated with the

273 percentage of top species in a web, the percentage of detritivores in the web, variation in the number of

274 consumers and links per taxon, and the mean path length across the network (Table 2). An example of a

275 web with a high positive PC1 score contains only detritivores (e.g. bacteria), which are all top species in

276 this context (Fig. 3b). The second principal axis (PC2) explained 25\% of the variation and was related to

277 trophic redundancy and variation in prey and predator strategies. Webs with a positive score for PC2 (Fig.

278 3c) tended to have more species, and these species were intermediate detritivore species (i.e. bacteria) and 
279 had higher trophic similarity and greater variation in the number of prey per taxon (Table 2). Webs on the 280 negative side of this axis (Fig. 3d) had fewer species and the species that dropped out were bacteria.

\section{Principal components analysis of climate variables and latitude}

282 The first two principal components explained $92 \%$ of the climatic variation across our 39 sites. The first 283 principal axis (PC1) explained 78\% of the variation. Sites with high scores on this axis were at high 284 latitudes, had short growing seasons with low mean temperatures and precipitation, and had high annual variation in both of these variables (Table 3). Sites representative of these conditions were located in the northern US and Canada (Fig. 1). Sites with low scores are located at low latitudes and experience higher mean temperatures and precipitation, but lower variability in both variables (Table 3). These sites are located in the south-eastern US. PC2 explained 14\% the climatic variation across our 39 sites. Sites with positive scores had a high mean diurnal temperature range.

\section{Resource availability, food chain length, and food web complexity}

The hypothesized positive relationships between resource availability measured as bacterial abundance and measures of complexity and chain length were not observed. Bacterial abundance showed no relationship with any of the food web metrics at either the pitcher or site scale and was absent from all best-fit models (Tables 4 and 5).

\section{Habitat size, food chain length, and food web complexity}

Pitcher volume, which is a measure of ecosystem size, was positively correlated with the number of links per species, species richness, mean trophic level, chain length, and the percent of omnivores, and was negatively correlated with variation in links per species at the pitcher scale (Table 4). At the site scale, variation in pitcher volume was positively correlated with structural turnover in the clustering coefficient

301 (Table 5; Fig. 4d). As predicted, we observed increases in several measures of web complexity with 302 ecosystem size at the pitcher scale and increases in structural turnover with the CV of ecosystem size at 
the site scale. However, chain length increased with ecosystem size only at the pitcher scale and showed no relationship with variation in pitcher volume at the site scale.

\section{Nitrogen deposition, food chain length, and food web complexity}

Nitrogen deposition, which was predicted to have a negative effect on complexity and chain length metrics, showed no relationship with food web metrics and was not a significant predictor in any of the best-fitting models.

\section{Predator-prey interactions, food chain length, and food web complexity}

Mosquito abundance was not correlated with food web structure at the pitcher scale. However, variation in mosquito abundance at the site scale was positively correlated with structural turnover in two measures

312 of chain length - mean trophic level and mean chain length (Table 4; Fig 4 a, b). Although the

313 hypothesized relationship between mosquito abundance and chain length was observed at the site scale,

314 food web complexity did not increase with mosquito abundance at the pitcher scale and variation in 315 mosquito abundance within site did not increase structural turnover in complexity metrics.

\section{Biogeographic correlates of food chain length, and food web complexity}

317 PC1, which is positively correlated with latitude (Table 3) was present in all of the best-fitting models 318 that explained more than $5 \%$ of the variation in food web structure (Tables 4,5 ). At the pitcher scale, PC1 319 was positively correlated with two measures of food web complexity - linkage density and species richness. Species richness was shown to follow the same patterns and increase with latitude in previous analyses of these data (Buckley et al., 2003; 2010). Structural turnover at the site scale showed a consistent negative relationship with PC1 for more than half of the food web metrics measured (Table 5; Fig. 5). Thus, variation in food web structure within sites was greater at lower latitudes. 
of the variance in food web structure unexplained at the pitcher scale (Table 4). At the site scale, predictor

327 variables explained more $(8 \%-35 \%)$ variance in structural turnover in food webs (Table 5).

\section{DISCUSSION}

Ecosystem size has been associated with increased chain length in both aquatic (Spencer \& Warren, 1996; Post, 2000; McHugh et al., 2010) and terrestrial (Takimoto et al., 2008) ecosystems. Our measure of ecosystems size, pitcher volume had a positive effect on both measures of chain length and measures of food web complexity, linkage density, species richness, and the percentage of omnivores in the web. Previous research on this data set has shown that species richness of arthropods, rotifers, and bacteria all increase with pitcher volume (Buckley et al., 2010). Our results suggest that as species richness increases with pitcher volume, an increasing number of omnivores are added to the web. density. Omnivore presence increases measures of chain length because the majority of omnivores in the Sarracenia food web feed at high trophic levels.

Resource availability showed no relationship with food web structure at the pitcher or site scales. One possibility why the predicted relationship was not observed is that bacterial abundance is not an appropriate measure for resource availability. The true resources are prey items that are captured by the plant. Although a bottom-up effect of prey abundance on bacterial abundance has been demonstrated repeatedly in the Sarracenia system (Kneitel \& Miller, 2002; Miller et al., 2002; Hoekman, 2010a), it is possible that bacterial abundance is a poor surrogate for resource availability due to sampling effects (i.e. only a fraction of the bacterial species can be cultured) or because abundance may not reflect productivity 346 because of ongoing consumption of bacteria by higher trophic levels.

Although mosquito abundance had no effect on food web structure at the pitcher scale, increased variation in mosquito abundance between pitchers was positively correlated with structural turnover in chain length and mean trophic level within sites. Mosquito larval density varied from 0 to over 11 larvae 
per ml. The simple presence of W. smithii can increase metrics related to chain length (Kitching, 2001;

351 Post \& Takimoto, 2007), or at high densities, extirpate intermediate consumers through predation

352 (Addicott, 1974; Kneitel, 2007), concomitantly decreasing chain length. Mosquito abundance was not

353 related to any measures of food web complexity, suggesting that the observed keystone effects of

354 increased bacterial and protozoan diversity (Cochran-Stafira \& von Ende, 1998; Peterson et al., 2008)

355 were not manifested in food web metrics related to complexity (consistent with Kneitel and Miller, 2002).

The ability to assess the influence of broad-scale climatic variables on food web structure was a novel aspect of this study. No single climate variable explained variation in food web structure due to colinearity among climate variables. Instead, PC1, which was derived from a suite of climate variables, captured latitudinal variation in temperature and precipitation across our sites and allowed us to specifically test predictions related to the biogeographic patterns of species richness and compositional turnover in the Sarracenia food web (Buckley et al., 2003; 2010). Our original prediction was that metrics related to chain length and complexity would increase with latitude. Specifically, we found that the complexity metric linkage density increased with latitude and this was most likely due to higher 364 species richness of arthropods and rotifers (which represent $75 \%$ of the omnivores in the species pool) at 365 higher latitudes (Buckley et al., 2003; 2010). We also confirmed the prediction that structural turnover 366 would follow the same pattern as compositional turnover and have an inverse relationship with latitude 367 (Buckley et al., 2010). Increased compositional and structural turnover at lower latitudes implies that when certain species drop out of the web they are either replaced by a trophically different species, or not 369 replaced at all. A positive correlation between compositional turnover and structural turnover is likely 370 when communities are assembled from a species pool with low functional or trophic redundancy (Baiser $371 \&$ Lockwood, 2011). As a result, when a new species is added to a web it likely represents a new trophic 372 strategy and hence an alteration in network structure.

Few other studies have examined broad-scale correlates of food web structure over such a large 374 spatial scale. The Sarracenia web may be exceptional because the species pool of macroinvertebrates is 
375 invariant over a large geographic area (Buckley et al., 2010). However, our results provide a general

376 framework for understanding how patterns of compositional turnover and species richness influence

377 variation in food web. If species are replaced by trophically unique species or not at all, as in the case of

378 the low latitude Sarracenia food webs, compositional and structural turnover may be tightly linked. If a

379 species pool has high trophic redundancy, species replacements will be trophically similar and food web

380 structure may be conserved independent of compositional turnover. The degree to which both trophic

381 redundancy is related to the richness of a species pool and patterns of species richness are correlated with

382 broad-scale variables, are important factors in understanding the relationship between food web structure

383 and biogeography. Trophic or functional redundancy within a given web mitigates against secondary

384 extinctions (Borvall et al. 2000) and trophically redundant species are less vulnerable to cascading

385 extinctions (Petchey et al. 2009). Trophic redundancy in the regional species pool may have a similarly

386 stabilizing effect on food web structure as species composition turns over.

Overall, our results show that the commonly observed relationship between ecosystem size and

388 food chain length (Spencer \& Warren, 1996; Post, 2000; Takimoto et al., 2008; McHugh et al., 2010) is

389 extended to several measures of network structure in the Sarracenia food web and that biogeographic

390 patterns of species richness and compositional turnover influence food web structure. However, our

391 predictor variables leave a large portion of variability in food web structure unexplained. We suggest that

392 stochastic assembly processes related to dispersal and arrival order and timing of propagules (Knietal and

393 Miller, 2003; Chase, 2010) that are not captured in our snapshot data set may be the driving influence of

394 food web structure in the Sarracenia system. A study assessing assembly trajectory is necessary to

395 explicitly test the hypothesis that stochastic assembly processes are the main determinant of network

396 structure in the Sarracenia food web. 


\section{ACKNOWLEDGEMENTS}

400 We thank Mike Moran and Junhua Zhang (Environment Canada, Air Quality Research Division) for

401 providing nitrogen deposition estimates for our sites using their AURAMS model. Support for this

402 research was provided by NSF grants 0083617 to TEM, AME, and NJG, and 0541680 to AME.

403 


\section{REFERENCES}

405

406

407

408

409

410

411

412

413

414

415

416

417

418

419

420

421

422

423

424

425

426

427

Addicott, J.F. (1974) Predation and prey community structure: an experimental study of the effect of mosquito larvae on the protozoan communities of pitcher plants. Ecology, 55, 475-492.

Arim, M., Bozinovic, F. \& Marquet, P.A. (2007) On the relationship between trophic position, body mass and temperature: reformulating the energy limitation hypothesis. Oikos, 116, 1524-1530.

Baiser, B. \& Lockwood, J. L. (2011) The relationship between functional and taxonomic homogenization. Global Ecology and Biogeography, 20, 134-144.

Beckerman, A.P., Petchey, O.L. \& Warren, P.H. (2006) Foraging biology predicts food web complexity. Proceedings of the National Academy of Sciences USA, 103, 13745-13749.

Bledzki, L.A. \& Ellison, A.M. (2003) Diversity of rotifers from northeastern USA bogs with new species records for North America and New England. Hydrobiologia, 385, 193-200.

Bradshaw, W.E. \& Creelman, R.A. (1984) Mutualism between the carnivorous purple pitcher plant Sarracenia purpurea and its inhabitants. American Midland Naturalist, 112, 294-304.

Bradshaw, W.E., Holzapfel, C.M., Kleckner, C.A. \& Hard, J.J. (1997) Heritability of development time and protandry in the pitcher-plant mosquito, Wyeomia smithii. Ecology, 78, 969-976.

Buckley, H. L., Miller, T., Ellison, A. M. \& Gotelli, N. J. (2003) Reverse latitudinal trends in species richness of pitcher-plant food webs. Ecology Letters, 6, 825-829.

Buckley, H. L., Miller, T. E., Ellison, A. M. and Gotelli, N. J. (2010) Local- to continental-scale variation in the richness and composition of an aquatic food web. Global Ecology and Biogeography, 19, 711-723.

Burnham, K.P. \& Anderson, D.R. (2002) Model Selection and Multimodel Inference: a Practical Information Theoretic Approach, 2nd edn. Springer-Verlag, New York.

Butler, J. L., \& Ellison, A. M. (2007) Nitrogen cycling dynamics in the carnivorous northern pitcher plant, Sarracenia purpurea. Functional Ecology, 21, 835-843. 
Butler, J.L., Gotelli, N.J. \& Ellison, A.M. (2008) Linking the brown and green: nutrient transformation and fate in the Sarracenia microecosystem. Ecology, 89, 898-904.

Camacho, J., Guimer`a, R. \& Amaral, L.A.N. (2002) Robust patterns in food web structure. Physical Review Letters, 88, 228102.

Chase, J.M. (2010). Stochastic community assembly causes higher biodiversity in more productive environments. Science, 328, 1388-1391.

Cochran-Stafira, D.L. \& von Ende, C.N. (1998) Integrating bacteria into food webs: studies with Sarracenia purpurea inquilines. Ecology, 79, 880-898.

Dunne, J.A. 2009. Food webs. in the Complex Networks and Graph Theory section of the Encyclopedia of Complexity and Systems Science, (ed. Meyers, R.A.) Springer, NewYork. Pages 3661-3682.

Dunne, J. A., Williams, R. J. \& Martinez, N. D. (2002a) Network structure and biodiversity loss in food webs: robustness increases with connectance. Ecology Letters, 5, 558-567

Dunne, J. A., Williams, R. J. \& Martinez, N. D. (2002b) Food-web structure and network theory: the role of connectance and size. Proceedings of the National Academy of Sciences USA, 99, 1291712922.

Ellison, A.M. (2006) Nutrient limitation and stoichiometry of carnivorous plants. Plant Biology, 8, 740747.

Ellison, A.M. \& Gotelli, N.J. (2002) Nitrogen availability alters the expression of carnivory in the northern pitcher plant, Sarracenia purpurea. Proceedings of the National Academy of Sciences USA, 99, 4409-4412.

Ellison, A.M., Gotelli, N.J., Brewer, J.S., Cochran-Stafira, L., Kneitel, J., Miller, T.E., Worley, A.S. \& Zamora, R. (2003) The evolutionary ecology of carnivorous plants. Advances in Ecological. Research, 33, 1-74.

Ellison, A.M., Buckley, H.L., Miller, T.E. \& Gotelli, N.J. (2004). Morphological variation in Sarracenia purpurea (Sarraceniaceae): geographic, environmental, and taxonomic correlates. American Journal of Botany, 91, 1930-1935. 
471

472

Forsyth, A.B. \& Robertson, R.J. (1975) $K$ reproductive strategy and larval behaviour of the pitcher plant sarcopagid fly, Blaesoxipha fletcheri. Canadian Journal of Zoology., 53, 174-179.

Fretwell, S.D. (1987) Food-chain dynamics: the central theory of ecology. Oikos, 50, 291-301.

Gotelli, N.J. \& Ellison, A.M. (2002) Nitrogen deposition and extinction risk in the northern pitcher plant, Sarracenia purpurea. Ecology, 83, 2758-2765.

Gotelli, N.J. \& Ellison, A.M. (2006) Food-web models predict species abundance in response to habitat change. PLoS Biology, 44, e324.

Hairston, N. G., Smith, F. E. \& Slobodkin, L. B. (1960) Community structure, population control, and competition. American Naturalist, 94, 421-425.

Hamilton, R., Reid, J. W. \& Duffield, R. M. (2000) Rare copepod, Paracyclops canadensis (Willey), common in leaves of Sarracenia purpurea L. Northeastern Naturalist, 7, 17-25.

Harvey, E. \& Miller, T. E. (1996) Variance in composition of inquiline communities in leaves of Sarracenia purpurea L on multiple spatial scales. Oecologia, 108, 562-566.

Heard, S. B. (1994) Pitcher plant midges and mosquitoes: a processing chain commensalism. Ecology, 75, $1647-1660$.

Hoekman, D. (2010a) Relative importance of top-down and bottom-up forces in food webs of Sarracenia pitcher communities at a northern and a southern site. Oecologia, DOI: 10.1007/s00442-010$1802-2$.

Hoekman, D. (2010b) Turning up the heat: Temperature influences the relative importance of top-down and bottom-up effects. Ecology, 91, 2819-2825.

Jenkins, B., Kitching, R.L. \&Pimm S.L. (1992) Productivity, disturbance and food web structure at a local spatial scale in experimental container habitats. Oikos, 65, 249-255

Kaunzinger, C.M.K. \& Morin, P.J. (1998) Productivity controls food-chain properties in microbial communities. Nature, 395, 495-497.

Kitching, R.L. (2000) Food webs and container habitats: the natural history and ecology of phytotelmata, Cambridge University Press, Cambridge. 
Kitching, R.L. (2001) Food webs in phytotelmata: ‘bottom-up' and 'top-down' explanations for community structure. Annual Review of Entomology, 46, 729-760.

Kneitel J.M. (2007) Intermediate-consumer identity and resources alter a food web with omnivory. Journal of Animal Ecolology, 76, 651-659.

Kneitel J.M. \& Miller, T.E. (2002) Resource and top-predator regulation in the pitcher plant (Sarracenia purpurea) inquiline community. Ecology, 83, 680-688.

Kneitel J.M. \& Miller, T.E. (2003) Dispersal rates affect species composition in metacommunities of Sarracenia purpurea inquilines. American Naturalist, 162, 165-171.

Koopman, M.M., Fuselier, D.M., Hird, S. \& Carstens, B.C. (2010) The carnivorous pale pitcher plant harbors diverse, distinct, and time-dependent bacterial communities. Applied and Environmental Microbiology, 76, 1851-1860.

Marks, J.C., Power, M.E. \& Parker, M.S. (2000) Flood disturbance, algal productivity, and interannual variation in food chain length. Oikos, 90, 20-27.

Martinez, N.D. (1994) Scale-dependent constraints on food-web structure. American Naturlist, 144, 935953.

Martinez, N. D. \& Lawton, J. H. (1995) Scale and food-web Structure-from local to global. Oikos, 73, $148-154$.

May, R.M. (1973) Stability and Complexity in Model Ecosystems. Princeton University Press, Princeton NJ.

McHugh, P.A., McIntosh, A.R. \& Jellyman, P.G. (2010) Dual influences of ecosystem size and disturbance on food chain length in streams. Ecology Letters, 13, 881-890.

McKenney, D., Papadopol, P., Campbell, K., Lawrence, K. \& Hutchinson, M. (2006) Spatial models of Canada-and North America-wide 1971/2000 minimum and maximum temperature, total precipitation and derived bioclimatic variables. Forestry Research Applications Technical Note No. 106. Canadian Forest Service, Great Lakes Forestry Centre, Sault Ste. Marie, Canada. 
Miller, T.E., Horth, L., \& Reeves, R.H. (2002) Trophic interactions in the phytotelmata communities of the pitcher plant, Sarracenia purpurea. Community Ecology, 3, 109-116.

Miller, T. E. \& Kneitel, J. M. (2005) Inquiline communities in pitcher plants as a prototypical metacommunity. In Metacommunities: Spatial Dynamics and Ecological Communities. (eds. Holyoak, M., Leibold, M. A. \& Holt, R. D) University of Chicago Press, Chicago, pp. 122-145. Moran, M. D., Zheng, Q., Pavlovic, R., Cousineau, S., Bouchet, V. S., Sassi, M., Makar, P. A., Gong, W. \& Stroud, C. (2008) Predicted acid deposition critical-load exceedances across Canada from a one-year simulation with a regional particulate-matter model. Proc. 15th Joint AMS/A\&WMA Conf. on Applications of Air Pollution Meteorology, 21-24 January, New Orleans, American Meteorological Society, Boston, 20 pp., online available at: http://ams.confex.com/ ams/pdfpapers/132916.pdf.

Paine, R. T. (1969) The Pisaster-Tegula interaction: prey patches, predator food preferences and intertidal community structure. Ecology, 50, 950-61.

Peterson, C.N., Day S., Wolfe, B.E., Ellison, A.M., Kolter R. \& Pringle A. (2008) A keystone predator controls bacterial diversity in the pitcher-plant (Sarracenia purpurea) microecosystem. Environmental Microbiology, 10, 2257-2266.

Pimm, S.L. (1982) Food Webs. Chapman \& Hall, London.

Post, D.M. (2002) The long and short of food-chain length. Trends in Ecology and Evolution, 17, 269277.

Post, D.M. \& Takimoto, G. (2007) Proximate structural mechanisms for variation in food-chain length. Oikos, 116, 775-782.

Post, D.M., Pace, M.L. \& Hairston, N.G. (2000) Ecosystem size determines food-chain length in lakes. Nature, 405, 1047-1049.

Power, M.E., Parker, M.S. \& Wootton, J.T. (1996) Food webs in space: an island biogeographic perspective. In: Food Webs (eds Polis, G.A. \& Winemiller, K.O.). Chapman \& Hall, New York, pp. 286-297. 
Schmitz, O.J. (2006) Predators have large effects on ecosystem properties by changing plant diversity, not plant biomass. Ecology, 87, 1432-1437.

Schmitz, O.J. (2010) Resolving Ecosystem Complexity. Princeton University Press, Princeton.

Schoener, T.W. (1989) Food webs from the small to the large. Ecology, 70, 1559-1589.

Spencer, M. \& Warren, P.H. (1996) The effects of habitat size and productivity on food web structure in small aquatic microcosms. Oikos, 75, 419-430.

Srivastava, D.S., Kolasa, J., Bengtsson, J., Gonzalez, A., Lawler, S.P., Miller, T.E., Munguia, P., Romanuk, T., Schneider, D.C. \& Trzcinski, M.K. (2004) Are natural microcosms useful model systems for ecology? Trends in Ecology and Evolution, 19, 379-384.

Takimoto, G., Spiller, D.A. \& Post, D.M. (2008) Ecosystem size, but not disturbance, determines foodchain length on islands of the Bahamas. Ecology, 89, 3001-3007.

Townsend, C.R., Thompson, R.M., McIntosh, A.R., Kilroy, C., Edwards, E. \& Scarsbrook, M.R. (1998) Disturbance, resource supply, and food-web architecture in streams. Ecology Letters, 1, 200-209.

Vermaat, J.E., Dunne, J.A. \& Gilbert, A.J. (2009) Major dimensions in foodwebstructure properties. Ecology, 90, 278-282.

Williams, R. J. (2010) Network 3D Software. Microsoft Research, Cambridge, UK.

Woodward, G., Papantoniou, G., Edwards, F. \& Lauridsen, R. B. (2008) Trophic trickles and cascades in a complex food web: impacts of a keystone predator on stream community structure and ecosystem processes. Oikos, 117, 683-692.

Xu, R. (2003) Measuring explained variation in linear mixed effects models. Statistics in Medicine, 22, $3527-3541$. 
561 BIOSKETCH

562 Ben Baiser is a Postdoctoral Research Associate at Harvard Forest. He has interests in community 563 ecology, conservation biology, invasion ecology, and understanding the impact of global change on 564 biodiversity. 


\section{TABLES}

Table 1. Definitions of food web metrics. Each metric is assigned a metric "type". Complexity metrics relate to the number of nodes (i.e. species) and links. Chain length metrics relate to the number of trophic levels in a web. Type of taxa describes the proportions of taxa found in a given trophic role. Trophic

571 strategy relates to variation in the number and similarity of predators and prey among species in a web.

\begin{tabular}{|c|c|c|}
\hline Metric & Type & Definition* \\
\hline $\mathrm{C}$ & Complexity & $\begin{array}{l}\text { connectance, or the proportion of possible links realized. } \mathrm{C}=\mathrm{L} / \mathrm{S}^{2} \text {, where } \mathrm{L} \text { is number of } \\
\text { links and } \mathrm{S} \text { is the number of species }\end{array}$ \\
\hline S & Complexity & species richness \\
\hline LS & Complexity & linkage density $=\mathrm{L} / \mathrm{S}$, number of links per species \\
\hline Clust & Complexity & clustering coefficient, probability that two taxa linked to the same taxon are also linked \\
\hline Path & Complexity ${ }^{\S}$ & $\begin{array}{l}\text { characteristic path length, the mean shortest set of links (where links are treated as } \\
\text { undirected) between species pairs }\end{array}$ \\
\hline ChLen & Chain length & mean food chain length, averaged over all species \\
\hline TL & Chain length & short-weighted trophic level averaged across taxa \\
\hline Top & Type of taxa & percentage of top species in a web (taxa have no predators) \\
\hline Int & Type of taxa & percentage of intermediate species in a web (taxa with both predators and prey) \\
\hline Omn & Type of taxa & percentage of omnivores in a web (taxa that feed on more than one trophic level) \\
\hline Det & Type of taxa & percentage of detritivores in a web (taxa that feed on Basal resources) \\
\hline GenSD & Strategy & normalized standard deviation of generality (\# resources per taxon) \\
\hline VulSD & Strategy & normalized standard deviation of vulnerability (\# consumers per taxon) \\
\hline LinkSD & Strategy & normalized standard deviation of links (\# links per taxon) \\
\hline MaxSim & Strategy & mean across taxa of the maximum trophic similarity of each taxon to other taxa \\
\hline
\end{tabular}

573 *Definitions are taken from Dunn et al. (2009) and Vermatt et al. (2009). For further information on food

574 web metrics, see Dunn et al. (2009) and sources therein.

$575{ }^{\S}$ Path is negatively correlated with complexity. 
580 Table 2. Factor loadings for the first two principal components axis (PC1 and PC2) describing variation in 581 food web structure. PC1 explained $45 \%$ of the variation and PC2 explained $25 \%$. See Table 1 for web 582 metric definitions.

\begin{tabular}{lrr}
\hline Web Metric & PC1 & \multicolumn{1}{c}{ PC2 } \\
\hline S & -0.21 & 0.31 \\
LS & -0.30 & 0.20 \\
C & -0.33 & -0.18 \\
Top & 0.20 & -0.32 \\
Int & -0.23 & 0.36 \\
Det & 0.27 & 0.33 \\
Omn & -0.29 & -0.02 \\
GenSD & 0.06 & 0.45 \\
VulSD & 0.32 & -0.10 \\
LinkSD & 0.29 & 0.24 \\
TL & -0.33 & -0.03 \\
MaxSim & -0.10 & 0.36 \\
Path & 0.25 & 0.30 \\
Clust & -0.25 & 0.01 \\
ChLen & -0.28 & 0.001 \\
\hline
\end{tabular}

583 
584 Table 3. Factor loadings for the first two principal components axis (PC1 and PC2) describing climatic 585 variation across our 39 sites. PC1 explained $78 \%$ of the variation and PC2 explained $14 \%$. PC1 describes

586 latitudinal variation in temperature and precipitation. Sites with high scores on this axis were at high

587 latitudes, had short growing seasons with low mean temperatures and precipitation, and had high annual

588 variation in both of these variables. Sites representative of these conditions were located in the northern

589 US and Canada (Fig. 1). Sites with low scores are located at low latitudes and experience higher mean

590 temperatures and precipitation, but lower variability in both variables. Climate variables are defined in

591 Appendix S1.

\begin{tabular}{lrr}
\hline Variable & \multicolumn{1}{l}{ PC1 } & \multicolumn{1}{l}{ PC2 } \\
\hline MDT & -0.04304 & 0.722233 \\
CVMT & 0.334351 & 0.06211 \\
ATR & 0.32642 & 0.141781 \\
Ap & -0.30974 & -0.24194 \\
CVp & 0.219126 & 0.425786 \\
GR & -0.32155 & 0.209303 \\
MT & -0.33032 & 0.176812 \\
MMINT & -0.33329 & 0.118973 \\
MMXT & -0.32543 & 0.230974 \\
MMONP & -0.30975 & -0.2419 \\
Lat & 0.332285 & -0.11618 \\
\hline
\end{tabular}

592

593

594

595

596

597

598 
600 Table 4. Top ranked mixed models with site as a random effect describing network structure for the

601 Sarracenia food web. Metrics for which the top model was the null model (intercept only) or where the

$602 \Delta \mathrm{AIC}<2$ between the null model and the top model are not included. See Table 1 for web metric

603 definitions.

\begin{tabular}{llrrrr}
\hline Web Metric & Variable & Estimate (SE) & t-value & p-value & $\mathbf{R}^{\mathbf{2}^{*}}$ \\
\hline LS & Intercept & $2.95(0.05)$ & 55.19 & $<0.001$ & 0.05 \\
& PC1 & $0.07(0.02)$ & 3.57 & $<0.01$ & \\
& Vol & $0.26(0.04)$ & 7.26 & $<0.001$ & \\
S & Intercept & $10.76(0.18)$ & 59.19 & $<0.001$ & 0.05 \\
& PC1 & $0.24(0.06)$ & 3.85 & $<0.001$ & \\
& Vol & $0.82(0.12)$ & 7.01 & $<0.001$ & \\
TL & Intercept & $2.12(0.008)$ & 256.07 & $<0.001$ & 0.04 \\
& Vol & $0.03(0.005)$ & 6.02 & $<0.001$ & \\
ChLen & Intercept & $2.08(0.007)$ & 277.73 & $<0.001$ & 0.04 \\
& Vol & $0.03(0.005)$ & 5.93 & $<0.001$ & \\
Omn & Intercept & $0.27(0.007)$ & 35.96 & $<0.001$ & 0.04 \\
& Vol & $0.03(0.005)$ & 5.78 & $<0.001$ & \\
LinkSD & Intercept & $0.29(0.01)$ & 32.02 & $<0.001$ & 0.02 \\
& Vol & $-0.03(0.007)$ & 3.82 & $<0.001$ & \\
\hline
\end{tabular}

604

$605 * \mathbf{R}^{2}$ calculated using the methods of Xu (2003) for assessing the fit of mixed models.

606 
607 Table 5. Top ranked linear models describing structural turnover (CV of food web metrics) for the

608 Sarracenia food web. Only models significant at a P-value of 0.05 with an adjusted $\mathrm{R}^{2} \geq 0.05$ are shown.

609 See Table 1 for web metric definitions.

610

\begin{tabular}{|c|c|c|c|c|c|}
\hline Web Metric & Variable & Estimate (SE) & t-value & p-value & adj-R $R^{2}$ \\
\hline \multirow[t]{3}{*}{ ChLen } & Intercept & $0.04(0.004)$ & 10.0 & $<0.001$ & 0.35 \\
\hline & PC1 & $-0.003(0.004)$ & -3.86 & $<0.001$ & \\
\hline & Mosq & $0.008(0.002)$ & 3.43 & $<0.01$ & \\
\hline \multirow[t]{3}{*}{ TL } & Intercept & $0.05(0.005)$ & 10.15 & $<0.001$ & 0.33 \\
\hline & PC1 & $-0.003(0.001)$ & -3.98 & $<0.001$ & \\
\hline & Mosq & $0.008(0.003)$ & 2.93 & $<0.01$ & \\
\hline \multirow[t]{3}{*}{ Clust } & Intercept & $0.18(0.09)$ & 2.07 & $<0.05$ & 0.33 \\
\hline & PC1 & $-0.03(0.008)$ & -3.24 & $<0.01$ & \\
\hline & Vol & $0.34(0.14)$ & 2.40 & $<0.05$ & \\
\hline \multirow[t]{2}{*}{ Omn } & Intercept & $0.44(0.02)$ & 18.17 & $<0.001$ & 0.18 \\
\hline & $\mathrm{PC} 1$ & $-0.03(0.008)$ & -3.03 & $<0.01$ & \\
\hline \multirow[t]{2}{*}{ LS } & Intercept & $0.31(0.01)$ & 24.63 & $<0.001$ & 0.15 \\
\hline & PC1 & $-0.01(0.004)$ & -2.75 & $<0.01$ & \\
\hline \multirow[t]{2}{*}{ Int } & Intercept & $0.20(0.01)$ & 14.58 & $<0.001$ & 0.12 \\
\hline & PC1 & $-0.01(0.005)$ & 2.47 & $<0.05$ & \\
\hline \multirow[t]{2}{*}{ Det } & Intercept & $0.20(0.007)$ & 29.89 & $<0.001$ & 0.11 \\
\hline & PC1 & $-0.006(0.002)$ & -2.40 & $<0.05$ & \\
\hline \multirow[t]{2}{*}{$\mathbf{S}$} & Intercept & $0.27(0.01)$ & 26.82 & $<0.001$ & 0.09 \\
\hline & PC1 & $-0.008(0.004)$ & 2.19 & $<0.05$ & \\
\hline \multirow[t]{2}{*}{ MaxSim } & Intercept & $0.06(0.004)$ & 13.68 & $<0.001$ & 0.08 \\
\hline & PC1 & $-0.003(0.001)$ & -2.05 & $<0.05$ & \\
\hline
\end{tabular}

612 


\section{FIGURE LEDGENDS}

615 Figure 1. Map showing the 39 sites where Sarracenia food webs were sampled (solid circles) and

616 National Atmospheric Deposition (NADP) sites (open circles) used for modeling nitrogen deposition.

617 Figure 2. Main components of the Sarracenia food web. Captured prey is shredded by both midge

618 (Metriocnemus knabi) and flesh fly (Fletcherimyia fletcheri) larvae into particulate organic matter (POM)

619 and directly decomposed by Bacteria. Bacteria also feed on POM along with mites (Sarraceniopus

620 gibsoni) and rotifers (Habrotrocha rosa). Bacteria is consumed by protozoa, rotifers (which also prey on

621 protozoa), all of which are preyed upon by the top predators the larvae of the mosquito Wyeomyia smithii

622 and the sarcophagid fly F. fletcheri. Fletcherimyia larvae are cannibalistic and also prey upon on first-

623 and second-instar W. smithii larvae. This is an aggregated general version of the pitcher plant web. For

624 topological representation of actual webs see the inlay of Fig. 3.

625 Figure 3. Principal components analysis of food web metrics (See Table 1 for web metric definitions.)

626 calculated for 780 Sarracenia food webs. Component 1 is related to complexity and chain length and

627 component 2 is related to trophic redundancy and variation in prey and predator strategies. These two

628 components explain $70 \%$ of the variation in Sarracenia food web structure. Inlay, four networks (a,b,c,d)

629 representing the extremes of each axis. For these four food webs, arrows are drawn from their position in

630 the PCA plot to the food web. White nodes represent the resource (dead prey items), grey nodes represent

631 bacteria, and black nodes represent consumers.

632 Figure 4. Univariate models showing the relationship between variables (other than latitude) and

633 structural turnover (CV of food web metrics) for the Sarracenia food web at the site-scale $(P<0.05$ for all

634 models). See Table 1 for web metric definitions. 
635 Figure 5. Univariate models showing the relationship between PC1 and structural turnover (i.e. variation 636 in network structure between webs within each site as measured by the CV of each food web metric) for 637 the Sarracenia food web at the site-scale. Structural turnover significantly decreased $(P<0.05)$ with PC1 638 and thus latitude for a) Chain Length, b) Mean Trophic Level, c) Clustering Coefficient, d) \% Omnivores, 639 e) Linkage Density, f) \% Intermediate species, g) \% Detritivores, h) Species Richness, and i) Maximum 640 Trophic Similarity.

641

642

643

644

645

646

647

648

649

650

651

652

653

654 
655 Figure 1.

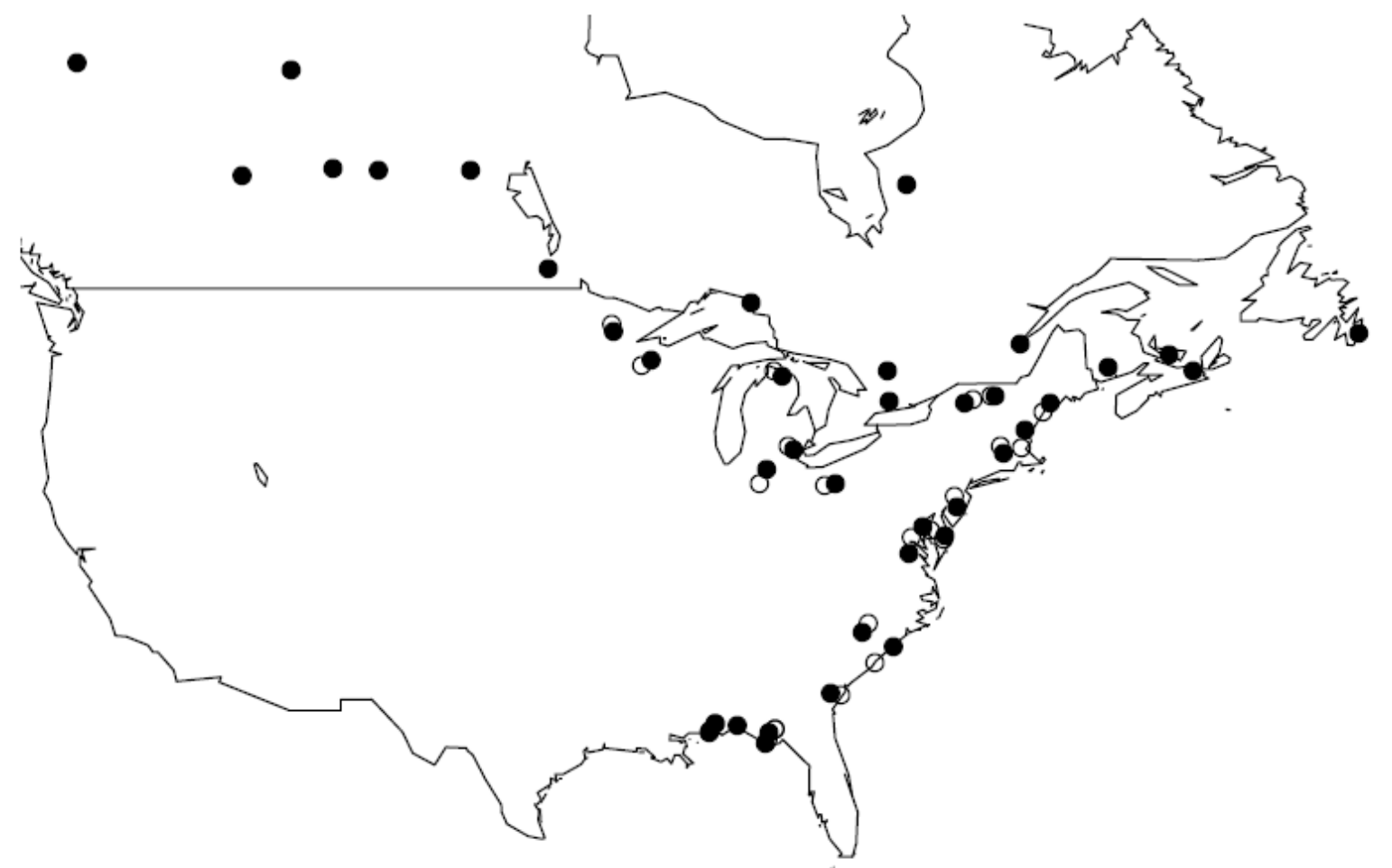

656

657

658

659

660

661

662

663

664

665

666 


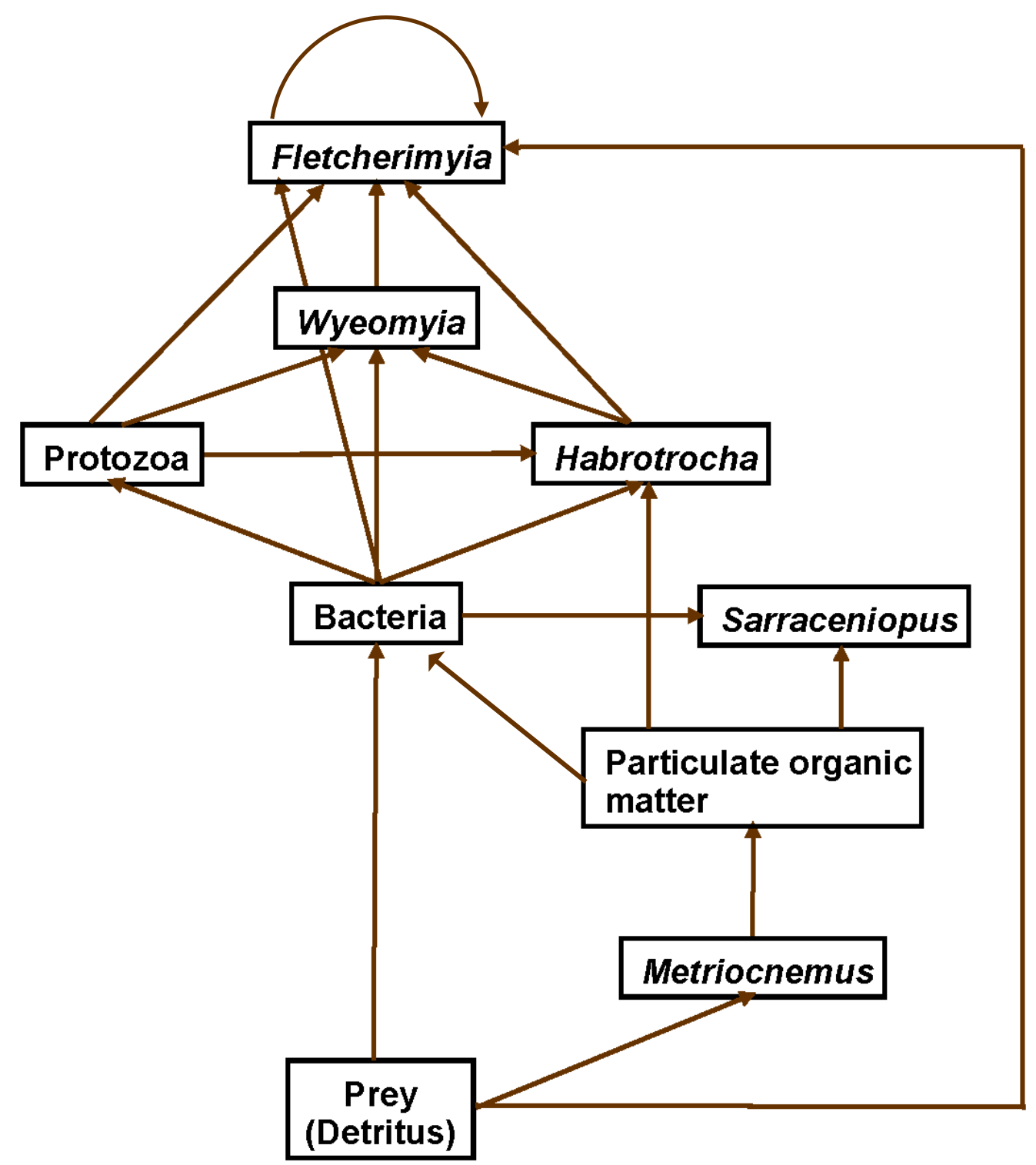

668 
673 Figure 3.

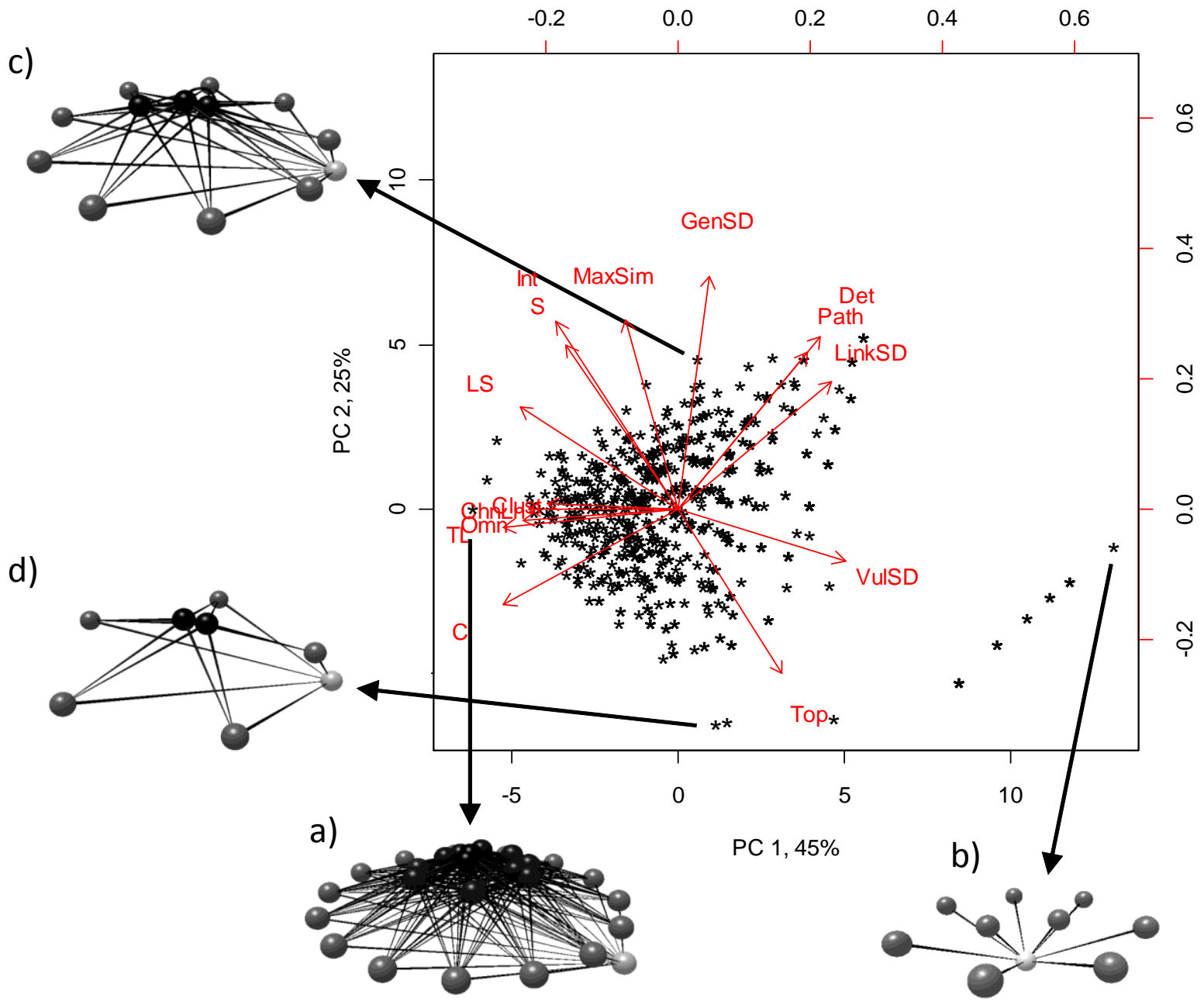

674

675

676

677

678

679 
Figure 4.

(a)

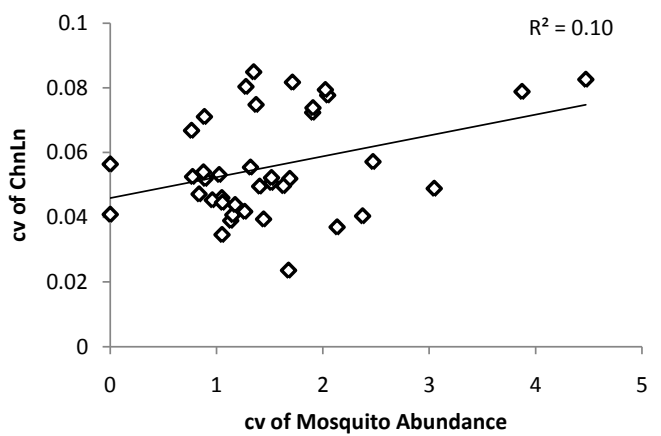

(c)

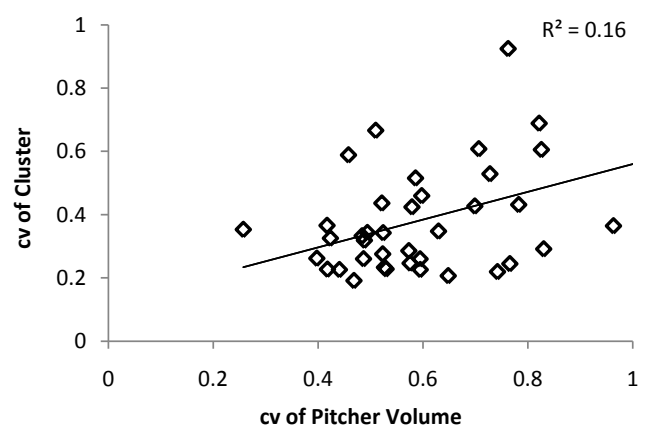

(b)

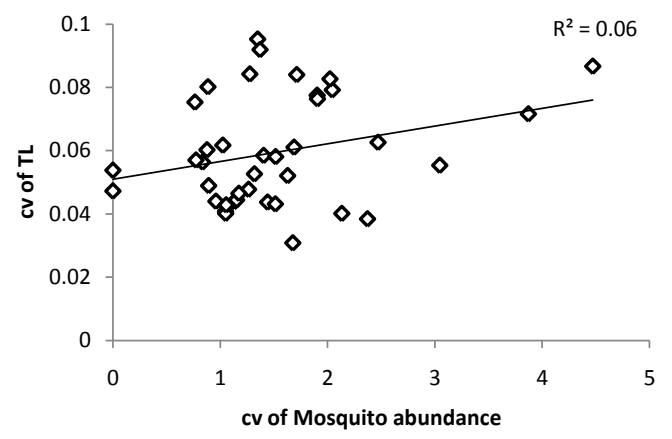

681

682

683

684

685

686

687

688

689 
Figure 5
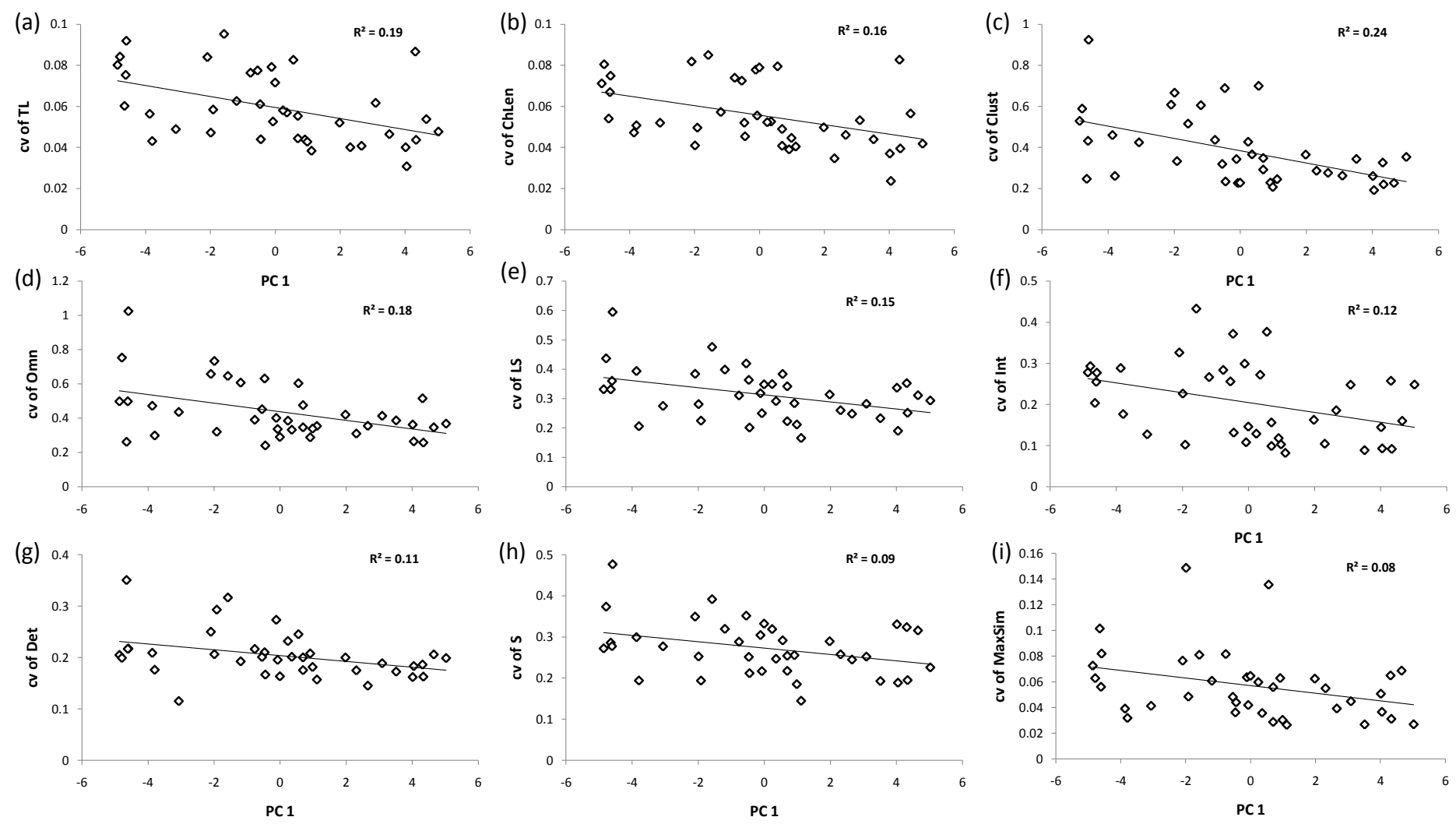
694 Climate variables (and latitude) used in climate variable principal components analysis and

695 regressions. See http://cres.anu.edu.au/outputs/anuclim.php for further information about climate

696 variables.

697 MT $=$ Annual Mean Temperature

698 MDTR = Mean Diurnal Range (Mean of monthly (max temp - min temp))

699 CVMT $=$ Temperature Seasonality (Coefficient of Variation)

$700 \mathrm{MMXT}=$ Mean Max Temperature

701 MMINT = Mean Min Temperature

702 ATR $=$ Temperature Annual Range

703 GR- Growing Season Days

$704 \quad \mathrm{AP}=$ Annual Precipitation

$705 \mathrm{MMONP}=$ Mean Monthly Precipitation

$706 \mathrm{CVP}=$ Precipitation Seasonality (Coefficient of Variation)

707 Lat $=$ Latitude

708

709

710

711

712

713

714

715

716

717

718 


\section{Appendix S2}

\section{Methods for modeling nitrogen deposition.}

721 Data on nitrogen deposition were available through National Atmospheric Deposition Data (NADP)

722 network only for sites in the United States (Fig. 1). Therefore, we used modeled depositional data for all

723 sites (i.e. including Canadian sites) provided by the AURAMS model (Moran et al. 2008). To estimate

724 the accuracy of the modeled data, we used linear regression to compare available empirical data from the

725 NADP sites with the modeled data. Where possible, NADP data were from 2001, the year in which

726 sampling occurred. When stations were not active during 2001, we used the closest full calendar year

727 data. Modeled data are for 2002 since NADP data ranged from 2001-2004. NADP and modeled

728 depositional data are quarterly totals of $\mathrm{NH}_{4}$ and $\mathrm{NO}_{3}$ in $\mathrm{mg} / \mathrm{L}$ (precipitation-weighted mean

729 concentration). We used the total nitrogen deposition $\left(\mathrm{N}=\mathrm{NH}_{4}+\mathrm{NO}_{3}\right)$ for the summer quarter (July-

730 September) as a predictor variable in our analyses of $S$. purpurea food webs. The modeled data was a

731 good fit to the NAPD data $\left(\mathrm{R}^{2}=0.43, \mathrm{p}\right.$-value $\left.<0.0001\right)$. 


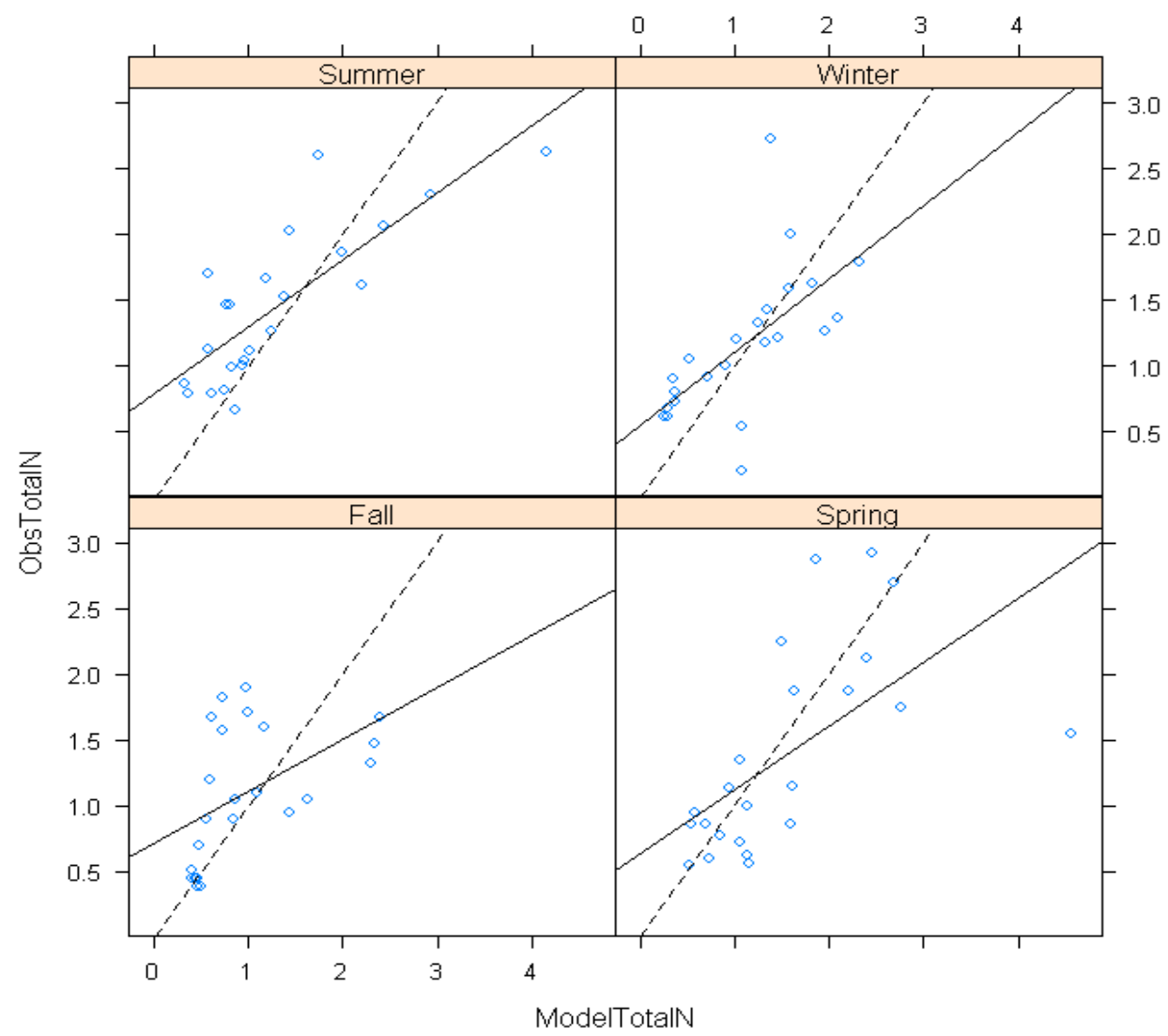

735

736

737 Figure 1. Quarterly/seasonal comparison of observed NAPD data for pitcher plant sites in the US with

738 modeled data from the AURAMS model (Moran et al. 2008). The observed regression line is solid and 739 the dotted line is a 1:1 relationship.

740

741

742

743

744 


\section{Appendix S3}

746 Correlations among climate variables and latitude. Analysis conducted using function 'r.corr.test' in

747 package 'Itm' in R v.2.11.1. The upper diagonal part contains correlation coefficient estimates and the

748 lower diagonal part contains corresponding p-values. Climate variables are defined in Appendix S1.

\begin{tabular}{|llllllllllll|}
\hline & MT & MDT & CVMT & MMINT & MMXT & GR & ATR & Ap & CVp & MMONP & Lat \\
MT & $* * * * *$ & 0.274 & -0.926 & 0.997 & 0.997 & 0.987 & -0.891 & 0.783 & -0.488 & 0.783 & -0.974 \\
MDT & 0.091 & $* * * * *$ & -0.051 & 0.195 & 0.348 & 0.28 & 0.082 & -0.093 & 0.231 & -0.092 & -0.255 \\
CVMT & $<0.001$ & 0.759 & $* * * * *$ & -0.94 & -0.907 & -0.892 & 0.987 & -0.9 & 0.644 & -0.9 & 0.927 \\
MMINT & $<0.001$ & 0.234 & $<0.001$ & $* * * * *$ & 0.987 & 0.982 & -0.916 & 0.807 & -0.518 & 0.807 & -0.972 \\
MMXT & $<0.001$ & 0.03 & $<0.001$ & $<0.001$ & $* * * * *$ & 0.985 & -0.862 & 0.755 & -0.457 & 0.755 & -0.97 \\
GR & $<0.001$ & 0.084 & $<0.001$ & $<0.001$ & $<0.001$ & $* * * * *$ & -0.863 & 0.748 & -0.418 & 0.748 & -0.946 \\
ATR & $<0.001$ & 0.619 & $<0.001$ & $<0.001$ & $<0.001$ & $<0.001$ & $* * * * *$ & -0.898 & 0.634 & -0.898 & 0.881 \\
Ap & $<0.001$ & 0.575 & $<0.001$ & $<0.001$ & $<0.001$ & $<0.001$ & $<0.001$ & $* * * * *$ & -0.708 & 1 & -0.833 \\
CVp & 0.002 & 0.158 & $<0.001$ & 0.001 & 0.003 & 0.008 & $<0.001$ & $<0.001$ & $* * * * *$ & -0.708 & 0.577 \\
MMONP & $<0.001$ & 0.576 & $<0.001$ & $<0.001$ & $<0.001$ & $<0.001$ & $<0.001$ & $<0.001$ & $<0.001$ & $* * * * *$ & -0.833 \\
Lat & $<0.001$ & 0.117 & $<0.001$ & $<0.001$ & $<0.001$ & $<0.001$ & $<0.001$ & $<0.001$ & $<0.001$ & $<0.001$ & $* * * * *$
\end{tabular}


$762 \quad$ Appendix S4

763 Mixed effect models for the pitcher-scale analysis using function 'Ime' in package 'nIme' in $R$

764 v.2.11.1.

765 Random intercept only model (null model):

766 - $\operatorname{summary}($ Null $<-1$ me $($ webmetric $\sim 1$, random $=\sim 1 \mid$ Site, data $=$ web $))$

767 Global Model:

768

769

- $\quad$ summary $($ Global $<-$ lme $($ webmetric $\sim$ Lat + Long + Elev + Vol $+\mathrm{N}+$ Mosq + Bact, random $=$

$\sim 1 \mid$ Site, data $=$ web $))$

770 Univariate Model:

771 - $\operatorname{summary}($ Univariate $<-\operatorname{lme}($ webmetric $\sim$ Vol, random $=\sim 1 \mid$ Site, data $=$ web $))$

772

773

774

775

776

777

778

779

780 


\section{Appendix S5}

784 Xu's (2003) method for calculating the variance explained $\left(\mathrm{R}^{2}\right)$ by the fixed effects in a mixed-effects

785 model. The residual variance from the model with fixed effects $\left(\operatorname{Var}_{\text {fixed }}\right)$ is divided by residual variance of 786 a model containing only the random effect (i.e. null model) $\left(V a r_{\text {null }}\right)$. This quotient is subtracted from one.

$$
R^{2}=1-\left(\frac{\operatorname{Var}_{\text {fixed }}}{\text { Var }_{\text {null }}}\right)
$$

